News and Views

\title{
STRATEGIES TO ALLOW FAMILY VISITS TO ACUTE CARE UNITS DURING THE COVID-19 PANDEMIC
}

\author{
RANA MA ${ }^{1}$, ARIF $B^{1}$, PERVAIZ ${ }^{1}$, SIDDIQUI MH ${ }^{2}$, RAZA $S^{1}$, HASHMI $M^{1}$, HAFEEZ MM $^{2 *}$ \\ ${ }^{I}$ Intensive Care Unit, Bahria Town International Hospital, Lahore-Pakistan \\ ${ }^{2}$ Department of Medicine, Akhtar Saeed Medical College Lahore, Pakistan \\ ${ }^{3}$ Department of Medicine, Expert Doctor Private Limited, Lahore-Pakistan \\ *Corresponding author email: mansoorhafeez140@gmail.com
}

\section{Keywords}

social withdrawal, health communications, Intensive care units, COVID-19 Pandemics, communicable illnesses Received $17^{\text {th }}$ January 2021; Revised $23^{\text {th }}$ July 2021; Published online $28^{\text {th }}$ July 2021

\section{Background}

From the start of severe acute respiratory syndrome coronavirus 2 (SARS-CoV-2) pandemic in Pakistan, hospital administration does not allow the families to have close contact with their loved as seeing in the other countries. This restriction was due to inadequate understanding of the virus transmission or may be due to the lack of personal protective equipment (PPEs) and the measures designed to ensure the safe visits of families in the ICU are no longer considered efficient to preventing cross infection. To deliver the quality healthcare facilities, health care team must set up consensus with patients and their families. Building trust with patients and families at the first contact might help with tough decisions that may need to be made later. In Pakistan, where the family structure is very strong, it is difficult to persuade the family to keep their loved ones away from them. Normally, entry into the ICU is restricted. Because most ICU patients are immunocompromised, there is a set time and only a few guests are allowed to enter. COVID-19 is in a sensitive situation, as most regional laws prohibit guest entry to the COVID ICU, or it is in the ICU In
Abstract: During pandemics, hospital administration does not allow family members to visit their loved ones. There is a need to develop standards and processes that may be followed when a family member enters an ICU or ward prevent cross infection. These rules should also put in place during

Charge's discretion to allow family members to see their patients by using locally developed protocols. Most of the people have a fair desire to remain close to their relative, especially in the latter stage of life, consider this rule unethical. The goal of this study is to share our ideas and experiences concerning the benefits of giving permission to visitors for ICU entry during pandemic and to identify barriers that restrict the presences of relative (close family friends) in ICUs. Only by identifying the potential causes we will be able to investigate and device practical ways to sort out this problem.

Advantages for healthcare team, patients, and the family members:

To be successful, respectful, and proportional, the therapeutic decisions that govern each patient's treatment require collaboration among the patients, their family members and healthcare providers, even during pandemics. Primarily, this needs proper communication via phone or video conversations, both of which are also practical and conceivable when it there is clear evidence of mortality. (Khan and Ullah, 2021; Ranjha et al., 2020; Sinuff et al., 2015). Even if these modes of communication are practical, they are insufficient and offer certain aim challenges, such as esteem for privacy and secrecy, and our social and cultural system never accepts sub 
distant ad nonphysical means of communication. The presence of family members should be physical to facilitate communication and treatment decisions in our heath care facilities. (Hart et al., 2020; Jan; Shaheen et al., 2020). It facilitates the efficient exchange of information; decision-making procedures are more transparent and understandable. It is found in many researches that the close proximity of family members in certain condition, particularly when patient coming out of deep sedation, and during lengthy non-invasive mechanical ventilation, because it can potentially decrease the chances of delirium, which is much more prevalent in COVID-19 patients as compare to other critically ill patients. Family members' physical presence is also important because it protects them from "complex grief." During the COVID-19 pandemic, it became difficult to be near to loved ones at the last stages of life (Cook et al., 2021). The ability to remain physically near to a loved one even now of death, if asked by family members, can minimize the chance of developing psychological difficulties that can last a long time. All the advantages associated with relatives' participation in ICUs far outweigh the pandemic dangers, which can be mitigated by proper measures. (Table-1)

Table-1 Advantages for healthcare team, patients, and the family members

\begin{tabular}{|c|c|}
\hline Benefit For the Critically Ill Patients & For The Patients' Families \\
\hline $\begin{array}{ll}\text { - } & \text { Respected patients' rights } \\
\text { - } & \text { Reduction of stress } \\
\text { - } & \text { Reduced sense of abandon } \\
\text { - } & \text { Prevent or reduce delirium } \\
\text { - } & \text { Increase patient motivation } \\
\text { - } & \text { Increased compliance to care } \\
\text { - } & \text { Psychological reassurance } \\
\text { - } & \text { Respect for patients' willingness }\end{array}$ & $\begin{array}{ll}\text { - } & \text { Help to increased understanding of patient } \\
\text { condition and treatment options } \\
\text { - } \\
\text { - } \\
\text { - } & \text { Redmiration of demand for closeness } \\
\text { - } & \text { Better acceptance of bad news } \\
\text { - } & \text { Prevention of complicated grief } \\
\text { - } & \text { Less feeling of powerlessness }\end{array}$ \\
\hline For Health Care Team & For All ICU Community \\
\hline $\begin{array}{ll}\text { - } & \text { Better information collection } \\
\text { - } & \text { Help in decision making } \\
\text { - } & \text { Increase appreciation and trust } \\
\text { - } & \text { Reduce moral distress } \\
\text { - } & \text { Prevent litigation }\end{array}$ & $\begin{array}{ll}\text { - } & \text { Better and simple communication } \\
\text { - } & \text { Guaranteed transparency } \\
\text { - } & \text { Shared decision making } \\
\text { - } & \text { Psychological wellbeing } \\
\text { - } & \text { Creation of family centered ICU } \\
\text { - } & \text { Improved patient and family satisfaction }\end{array}$ \\
\hline
\end{tabular}

\section{Strategies for Opening an ICU:}

1. Family members should be let access, even if just for a brief period.

Experts have emphasized, we must devise novel approaches to sustain active and successful relationships between the patients their family, and the healthcare team. By these innovative approaches it can be achieved in device respectable ways for the interaction of families and their patients (Simon et al., 2015). By allowing even brief meeting healthcare team can justify their information and support needs.
When opposed to no visit, even brief hospitalizations are usually meaningful to family and patients especially with Pakistani Culture. When done correctly, visits to COVID-19 or non-COVID-19 ICUs can be done safely and it will be the responsibility of the healthcare team to make sure all the standard of procedure should be followed to prevent any chance of cross infection.. (Phua et al., 2020).

2. Establishment of separate standard of procedures for COVID-19 and non-COVID19 ICUs.

[Cite: Rana, M.A., Arif, B., Pervaiz, R., Siddiquin, M.H., Raza, S., Hashmi, M., Hafeez, MM. (2021). Strategies to allow family visits to acute care units during the COVID-19 pandemic. Pak. J. Inten. Care Med., 2021: 7, https://doi.org/10.54112/pjicm.v2021i1.7]. 
Simple guidelines that are communicated by hospital administration are required to handle family members going to see the patients. Clear, well-defined, and explicit instructions should be given to relatives, and their implementation should be closely monitored. Family members must be safeguarded in COVID-19 ICUs with donning-and-doffing protocols of PPEs. (Sarma et al., 2020). To avoid the spread of covid-19 infection during a non-covid ICU visit, a rapid antigen test can be performed in addition to use appropriate PPEs.

3. It is mandatory to limit the number of visits by the family but is prudent to promote visits for those who will potentially in the benefit of patients the most.

There are different clinical phases of the illness when having a loved one close is more helpful, such as when the patients are coming out of deep sedation after prolonged noninvasive ventilation (Herridge et al., 2016). On the other hand, during prolong deep sedation, physical interaction is less important for patients, but it is more traumatic for the relative. There are periods in a patient's hospital stay when the presences of family member are crucial, such as after ICU admission when treatment options must be decided to save the life, or the minutes just prior death. Physical existence may be more helpful in protecting families from psychological damage under these unavoidably high-stress situations (O'Neill and Rothbard, 2017). If the frequency of admissions must be limited for organizational/administrative reasons or a shortage of PPE, it is advisable to prioritize visits that may give the most potential benefits to both patients and visitors under the conditions.

4. It is recommended to make a special ICU team that re-evaluate the protocols that restrict the visits of ICU at monthly basis.

Typically, during the start of a pandemic and as the crisis progresses, each hospital encounters a varied degree of patient flow, putting variable levels of stress on operators. Because every hospital has a limited supply of PPS, it is critical to limit family visits to the ICU, as this is directly connected to infection rates. As a result, to control the infection rate, every hospital must limit the visits of family members or guests to the ICU (Guest et al., 2019). Initially, the protocols created appeared to be ancillary to limiting the infection rate, but as time passes, these protocols must be changed in favor of the patients' benefit. As a result, it may be helpful to establish alternative protocols from the start, with varied restrictions for visits, and then adjust them automatically, for example, by connecting them to regional regulations.

5. Relatives and other guests must be warned about the dangers of entering COVID-19 locations.

The dangers of interacting with COVID-19 infected individuals must be explained. It's important to consider the advantages and disadvantages of visiting COVID-19-infected individuals (Dwivedi et al., 2020). Only some relatives are permitted to meet the patients if it is useful. Personal risk of contact with COVID-19-infected persons can be decreased, but it can never be eradicated. Family members and visitors must be appropriately informed about the risks of accessing facilities meant to treat patients with a severe infectious disease (Voo et al., 2020). In this case, hospital administration may be contacted to see if visitors to the COVID-19 area must sign a formal consent form.

6. The re-opening procedure should be communicated to the entire staff.

The circumstances of "coming out of the pandemic" positively in the next month's require special consideration from an organizational standpoint (Benita, 2021). All employees have suffered work and emotional exhaustion, and the modifications in internal norms imposed by isolation have unavoidably had an impact. As a result, it is critical that the method for reopening the wards be disseminated as widely as feasible amongst staff members, because any substantial change in the work atmosphere link to rise in stress for health-care employees (Puci et al., 2020).

7. Family members' physical attendance should not be restricted to ICUs.

The opening of the ICU for family visits affects not only the ICU but all the hospital wards. The ward is primarily responsible for the patient before to

[Cite: Rana, M.A., Arif, B., Pervaiz, R., Siddiquin, M.H., Raza, S., Hashmi, M., Hafeez, MM. (2021). Strategies to allow family visits to acute care units during the COVID-19 pandemic. Pak. J. Inten. Care Med., 2021: 7, https://doi.org/10.54112/pjicm.v2021i1.7]. 
admission to the ICU or following the patient's discharge from the ICU once the critical phase has passed (Ågård et al., 2015). In situations with fewer doctors and nurses, such as ICUs, this good clinical practice may be more challenging to adopt. Even and especially during the SARS-CoV-2 epidemic, it is advised that hospitals implement procedures and protocols that allow visitors and family members to see their patients, allowing the patient-centered care process to begin (Abrams et al., 2020; SIDDIQUE A, 2020; Tabassum et al., 2020).

\section{How to Begin the Opening Process:}

The following are required criteria for visitors for entrance of the hospital:

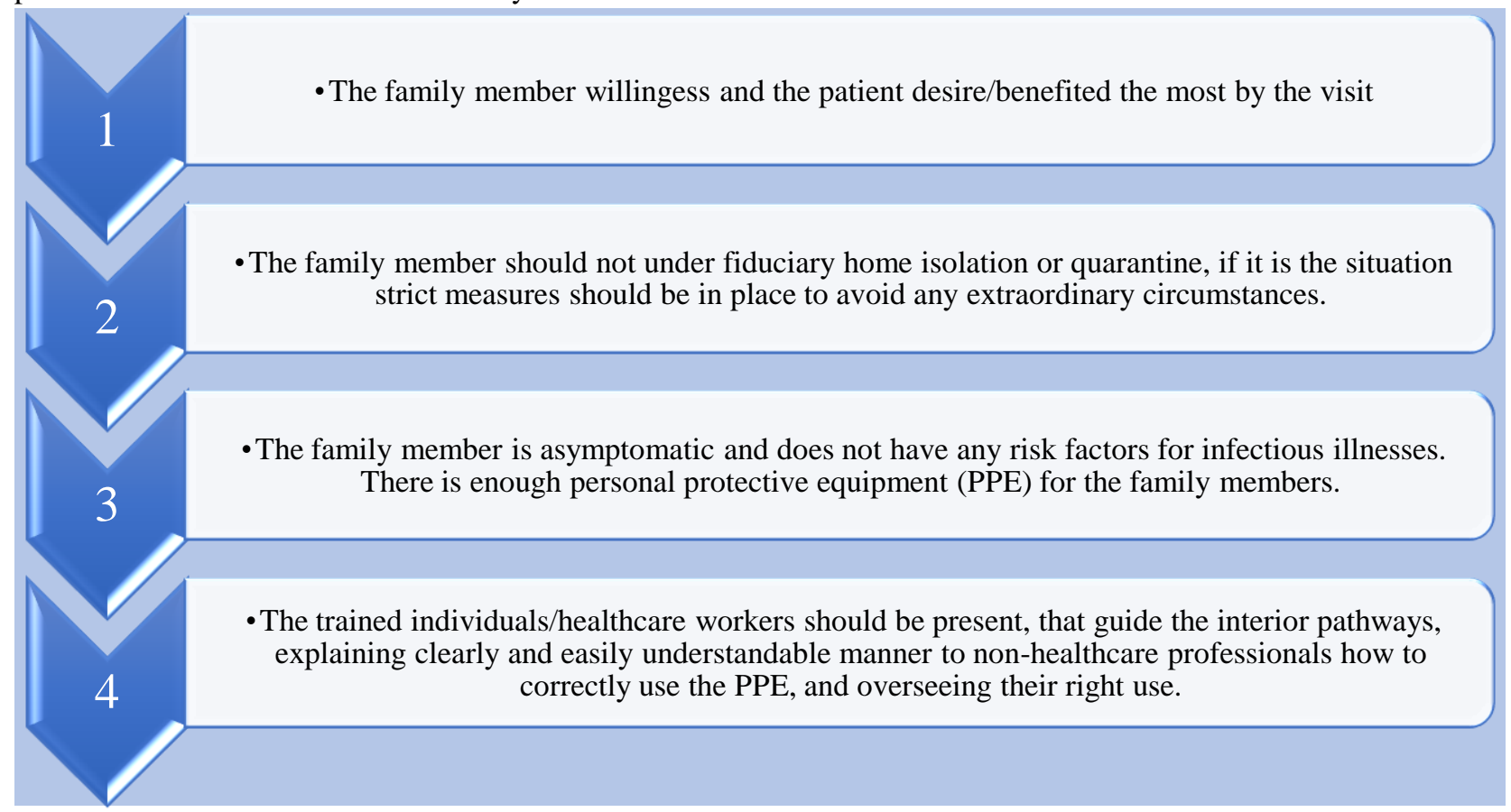

Given these circumstances, we feel the

following principles must be followed:

(A) Use strict, arranged processes to separate entry and exit routes, to guarantee proper preparation, interpersonal distance, hand washing, and the requirement to wear PPE (Bauchner et al., 2020). Once correctly executed, these procedures supply more than enough protection for patients about the threat of infection owing to family visits, as well as shield for family members from infection.

(B) When a family member arrives, adequate clinical surveillance, such as body temperature, flulike symptoms, and other risk factors, should be assessed using a questionnaire (Oliver et al., 2020). Optional infectious monitoring using fast antigenic testing, which can provide a response in minutes and are not too expensive, may provide an answer in minutes.
(C) To avoid individual loitering in waiting rooms, a good plan and timetable for the visits should be developed and discussed with the family members. Limit the number of people per visit, and if a daily visit isn't possible, ensure that family members can visit minimum once or twice per week (Ali J, 2020; Brooke and Clark, 2020; Mady et al., 2020). This could allow non-COVID-19 patients to avoid the stigma of a "closed" hospital, which is now unacceptably prevalent.

(D) Allow family members to see the patients in certain circumstances like prolonged hospitalization, cases with a poor short-term prognosis, and all cases of unique patient fragility (Mears and Kates, 2015).

From an organizational perspective, each healthcare institution may devise their own standard operating procedure for opening ICU visits, even during a pandemic, in the most efficient manner

[Cite: Rana, M.A., Arif, B., Pervaiz, R., Siddiquin, M.H., Raza, S., Hashmi, M., Hafeez, MM. (2021). Strategies to allow family visits to acute care units during the COVID-19 pandemic. Pak. J. Inten. Care Med., 2021: 7, https://doi.org/10.54112/pjicm.v2021i1.7]. 
possible, aiming to get into the clinical practice of family-centered medicine as soon as possible.
Table 2 summarizes the clinical, cultural, and logistical challenges, as well as solutions for overcoming them.

Table 2 shows how particular techniques might be used to overcome the hurdles that are likely to impede family presence in the ICU

\begin{tabular}{|c|c|c|}
\hline & Barriers to ICU visits & Strategies for implementation \\
\hline \multirow{4}{*}{ Clinical } & $\begin{array}{l}\text { When visiting CoViD-19 ICUs, there is a } \\
\text { risk of infection among families. }\end{array}$ & Donning and doffing procedures that are adequate \\
\hline & $\begin{array}{l}\text { In COVID-free critically sick patients, there } \\
\text { is a risk of infection. }\end{array}$ & $\begin{array}{l}\text { Before the visit, family members and guests are } \\
\text { screened. }\end{array}$ \\
\hline & $\begin{array}{l}\text { Employment with insufficient or inadequate } \\
\text { PPE }\end{array}$ & Clear instructions and monitoring are provided. \\
\hline & The visiting family member's physical pain & Preventive measures and staff availability \\
\hline \multirow{4}{*}{ Cultural } & The staff does not prioritize family visits. & $\begin{array}{l}\text { The ICU team is debriefing on the requirements } \\
\text { and desires of the family. }\end{array}$ \\
\hline & Staff employees are dissatisfied and tired. & $\begin{array}{l}\text { Adequate staff understanding of opening } \\
\text { advantages. }\end{array}$ \\
\hline & $\begin{array}{l}\text { Families' fear of additional opportunistic } \\
\text { illnesses. }\end{array}$ & $\begin{array}{l}\text { There is no indication in the literature that this is a } \\
\text { problem. }\end{array}$ \\
\hline & $\begin{array}{l}\text { Concerns about legal ramifications if tourists } \\
\text { become infected. }\end{array}$ & $\begin{array}{l}\text { Prior to the appointment, informed permission is } \\
\text { obtained. }\end{array}$ \\
\hline \multirow{4}{*}{ Logistical } & PPE is in short supply. & Visits are not authorized if the behavior continues. \\
\hline & $\begin{array}{l}\text { Time restrictions and a lack of personnel } \\
\text { availability }\end{array}$ & Extra personnel, as well as competent volunteers. \\
\hline & There are no processes or rules in place. & Creating common hospital/regional protocols. \\
\hline & $\begin{array}{l}\text { Due to an increase in ICU admissions, there } \\
\text { is insufficient/suboptimal space. }\end{array}$ & $\begin{array}{l}\text { Temporary restrictions on opening hours and } \\
\text { visitor capacity. }\end{array}$ \\
\hline \multicolumn{2}{|c|}{ Conclusions } & $\begin{array}{l}\text { reestablish good "humanizing" procedures not } \\
\text { for intensive but also non-intensive care units. }\end{array}$ \\
\hline
\end{tabular}

Unfortunately, the COVID-19 epidemic has imposed restricting or outlawing the approach of family members to ICUs. There is widespread perception in the healthcare provider community of how much agony these decisions, have inflicted in all those, who are involved in management of COVID-19 infected patients. The patients and families first and foremost, but also physicians and nurses are also facing the consequences. We may argue for a careful, progressive restoration of family visits based on current knowledge and the secure supply of PPE, keeping in view of patients respect and wishes of their family members. We feel there are no convincing reasons to restrict family members out of COVID-19 wards: it may not only be beneficial, but also necessary. All options should be examined in each hospital's particular environment to quickly

\section{Reference}

Abrams, E. M., Shaker, M., Oppenheimer, J., Davis, R. S., Bukstein, D. A., and Greenhawt, M. (2020). The challenges and opportunities for shared decision making highlighted by COVID-19. The Journal of Allergy and Clinical Immunology: In Practice.

Ågård, A. S., Egerod, I., Tønnesen, E., and Lomborg, K. (2015). From spouse to caregiver and back: A grounded theory study of post-intensive care unit spousal caregiving. Journal of advanced nursing 71, 1892-1903.

Ali J, A. Q., Hafeez MM, Malik A (2020). Clinical features, diagnosis and treatment of COVID19. Biol. Clin. Sci. Res. J 2020.

[Cite: Rana, M.A., Arif, B., Pervaiz, R., Siddiquin, M.H., Raza, S., Hashmi, M., Hafeez, MM. (2021). Strategies to allow family visits to acute care units during the COVID-19 pandemic. Pak. J. Inten. Care Med., 2021: 7, https://doi.org/10.54112/pjicm.v2021i1.7]. 
Bauchner, H., Fontanarosa, P. B., and Livingston, E. H. (2020). Conserving supply of personal protective equipment - a call for ideas. Jama 323, 1911-1911.

Benita, F. (2021). Human mobility behavior in COVID-19: A systematic literature review and bibliometric analysis. Sustainable Cities and Society 70, 102916.

Brooke, J., and Clark, M. (2020). Older people's early experience of household isolation and social distancing during COVID-19. Journal of clinical nursing 29, 4387-4402.

Cook, D. J., Takaoka, A., Hoad, N., Swinton, M., Clarke, F. J., Rudkowski, J. C., Heels-Ansdell, D., Boyle, A., Toledo, F., and Dennis, B. B. (2021). Clinician perspectives on caring for dying patients during the pandemic: A mixedmethods study. Annals of internal medicine 174, 493-500.

Dwivedi, Y. K., Hughes, D. L., Coombs, C., Constantiou, I., Duan, Y., Edwards, J. S., Gupta, B., Lal, B., Misra, S., and Prashant, P. (2020). Impact of COVID-19 pandemic on information management research and practice: Transforming education, work and life. International Journal of Information Management 55, 102211.

Guest, J. F., Keating, T., Gould, D., and Wigglesworth, N. (2019). Modelling the costs and consequences of reducing healthcareassociated infections by improving hand hygiene in an average hospital in England. BMJ open 9, e029971.

Hart, J. L., Turnbull, A. E., Oppenheim, I. M., and Courtright, K. R. (2020). Family-centered care during the COVID-19 era. Journal of Pain and Symptom Management 60, e93-e97.

Herridge, M. S., Moss, M., Hough, C. L., Hopkins, R. O., Rice, T. W., Bienvenu, O. J., and Azoulay, E. (2016). Recovery and outcomes after the acute respiratory distress syndrome (ARDS) in patients and their family caregivers. Intensive care medicine 42, 725738.

Jan, A. Socio-Economic and Psychological Impacts of Covid-19: A Case Study of Quarantined Village Ziarat Talash in Dir Lower, Pakistan. Liberal Arts and Social Sciences International Journal 4, 1-10.

Khan, K. M., and Ullah, N. (2021). Post COVID-19 financial distress in Pakistan: Prediction of corporate defaults at Pakistan Stock Exchange.
Liberal Arts and Social Sciences International Journal (LASSIJ) 5, 286-400.

Mady, A. F., Ramdan, O., Al Yousef, R., Ishag, A., Bakirova, G., Kuhail, A., Shahzad, S., ElEtreby, W., Mumtaz, S., Almozainy, S., Palacio, K., Aldamahshi, D., Alcazar, A., Alodat, M., Abdelrahman, B., and Harthy, A. (2020). COVID 19 critical care training surge experience for physicians in riyadh health cluster one, Saudi Arabia. Biological and Clinical Sciences Research Journal 2020, e041.

Mears, S. C., and Kates, S. L. (2015). A guide to improving the care of patients with fragility fractures, edition 2. Geriatric orthopaedic surgery \& rehabilitation 6, 58-120.

O’Neill, O. A., and Rothbard, N. P. (2017). Is love all you need? The effects of emotional culture, suppression, and work-family conflict on firefighter risk-taking and health. Academy of Management Journal 60, 78-108.

Oliver, N., Barber, X., Roomp, K., and Roomp, K. (2020). Assessing the impact of the COVID19 pandemic in Spain: large-scale, online, selfreported population survey. Journal of medical Internet research 22, e21319.

Phua, J., Weng, L., Ling, L., Egi, M., Lim, C.-M., Divatia, J. V., Shrestha, B. R., Arabi, Y. M., $\mathrm{Ng}$, J., and Gomersall, C. D. (2020). Intensive care management of coronavirus disease 2019 (COVID-19): challenges and recommendations. The lancet respiratory medicine 8, 506-517.

Puci, M. V., Nosari, G., Loi, F., Puci, G. V., Montomoli, C., and Ferraro, O. E. (2020). Risk perception and worries among health care workers in the covid-19 pandemic: findings from an Italian survey. In "Healthcare", Vol. 8, pp. 535. Multidisciplinary Digital Publishing Institute.

Ranjha, T. A., Rizvi, S. M. A. S., and Ahmad, J. (2020). Virtual Learning Strategies during COVID-19: A Case Study of The University of Lahore, Pakistan. Liberal Arts and Social Sciences International Journal (LASSIJ) 4, 427-441.

Sarma, R., Vig, S., Rathore, P., Pushpam, D., Mishra, S., Gupta, N., Garg, R., Kumar, V., Bharati, S. J., and Bhatnagar, S. (2020). Concerns of health care professionals managing nonCOVID patients during the COVID-19 pandemic: a descriptive cross-sectional study. Indian Journal of Palliative Care 26, S21.

[Cite: Rana, M.A., Arif, B., Pervaiz, R., Siddiquin, M.H., Raza, S., Hashmi, M., Hafeez, MM. (2021). Strategies to allow family visits to acute care units during the COVID-19 pandemic. Pak. J. Inten. Care Med., 2021: 7, https://doi.org/10.54112/pjicm.v2021i1.7]. 
Shaheen, M., Siraj, U., and Bhatti, M. N. (2020). Covid-19 Pandemic and its Politico-Economic Implications: A Study of Pakistan. Liberal Arts and Social Sciences International Journal 4, 42-51.

Siddique A, F. A., Idrees N, Hafez MM, Ali Q, MALIK A (2020). The epidemics of COVID19 Biol. Clin. Sci. Res. J 2020.

Simon, J., Porterfield, P., Bouchal, S. R., and Heyland, D. (2015). 'Not yet'and 'Just ask': barriers and facilitators to advance care planning - a qualitative descriptive study of the perspectives of seriously ill, older patients and their families. BMJ supportive \& palliative care 5, 54-62.

Sinuff, T., Dodek, P., You, J. J., Barwich, D., Tayler, C., Downar, J., Hartwick, M., Frank, C., Stelfox, H. T., and Heyland, D. K. (2015). Improving end-of-life communication and decision making: the development of a conceptual framework and quality indicators. Journal of pain and symptom management $\mathbf{4 9}$, 1070-1080.

Tabassum, S. A., Bibi, T., Tariq, F., Tariq, S., Raza, S., Hafeez, M. M., and Rana, M. A. (2020). Unusual leukemoid reaction in a COVID-19 patient: A case report. Biological and Clinical Sciences Research Journal 2020, e034.

Voo, T. C., Senguttuvan, M., and Tam, C. C. (2020). Family presence for patients and separated relatives during COVID-19: physical, virtual, and surrogate. Journal of bioethical inquiry 17, 767-772. view a copy of this licence, visit http://creativecommons.org/licen ses/by/4.0/.

(C) The Author(s) 2021

\section{(c) (†) (8)}

Open Access This article is licensed under a Creative Commons Attribution 4.0 International License, which permits use, sharing, adaptation, distribution and reproduction in any medium or format, as long as you give appropriate credit to the original author(s) and the source, provide a link to the Creative Commons licence, and indicate if changes were made. The images or other third party material in this article are included in the article's Creative Commons licence, unless indicated otherwise in a credit line to the material. If material is not included in the article's Creative Commons licence and your intended use is not permitted by statutory regulation or exceeds the permitted use, you will need to obtain permission directly from the copyright holder. To

[Cite: Rana, M.A., Arif, B., Pervaiz, R., Siddiquin, M.H., Raza, S., Hashmi, M., Hafeez, MM. (2021). Strategies to allow family visits to acute care units during the COVID-19 pandemic. Pak. J. Inten. Care Med., 2021: 7, https://doi.org/10.54112/pjicm.v2021i1.7]. 